Article

\title{
Decision Support on Monitoring and Disaster Management in Agriculture with Copernicus Sentinel Applications
}

\author{
Zina Mitraka ${ }^{1,2, * \mathbb{C}}$, Sofia Siachalou ${ }^{1}$, Georgia Doxani ${ }^{1}$ and Petros Patias ${ }^{1} \mathbb{C}$ \\ 1 Faculty of Engineering, School of Rural and Surveying Engineering, Aristotle University of Thessaloniki, \\ 54124 Thessaloniki, Greece; ssiacha@topo.auth.gr (S.S.); gdoxani@topo.auth.gr (G.D.); patias@auth.gr (P.P.) \\ 2 Foundation for Research and Technology Hellas, 70013 Heraklion, Greece \\ * Correspondence: mitraka@iacm.forth.gr; Tel.: +30-2810-391771
}

Received: 12 December 2019; Accepted: 6 February 2020; Published: 8 February 2020

check for updates

\begin{abstract}
The successful implementation of the European Commission's Common Agricultural Policy (CAP) and the insurance coverage in case of a natural disaster requires precise and regular mapping of crop types and detailed delineation of the disasters' effects by frequent and accurate controls. Free and open access policy to Copernicus Sentinel data offers a big volume of data to the users on a consistent and complete basis. Today, the Sentinels are involved in an increasing number of agriculture applications, but their effective exploitation is still being investigated and the development of efficient tools, aligned to the user's needs, is yet to be realised. To this end, the DiAS (Disaster and Agriculture Sentinel Applications) project proposes methods for decision support in agriculture using Sentinel data for crop type mapping, as well as mapping of the extend of fire and flood effects in agricultural areas. The DiAS Decision Support System (DSS) is designed in consultation with potential users in participatory approach and aims to provide a prototype tool, which provides assistance to the responsible paying agencies and insurance organizations to make decisions on farmers' subsidies and compensations. The DiAS DSS prototype and its functionalities are presented in this paper and its use is demonstrated through example applications for two test sites in Greece. The DiAS DSS demonstrates the necessity for the development of similar tools, as this emerges from the user's requirements, and wishes to stimulate and inspire further research and development.
\end{abstract}

Keywords: decision support system; agriculture monitoring; crop mapping; natural disasters effects

\section{Introduction}

The European Commission, acknowledging the important role of the agricultural sector, has introduced a set of regulations under the Common Agricultural Policy (CAP) keeping as a priority the sustainable development and management of natural resources. Additionally, in case of a natural disaster, the European Union (EU) and each state member offer recovery assistance to disaster-affected farmers to mitigate the impact of the problems caused. The authorities responsible for the successful implementation of CAP are the Paying Agencies (PAs) of the member states and, as for the insurance coverage, are various Insurance Organizations (IOs). The farmers submit, on an annual basis, a declaration of the crop types they cultivate to the PA of their country and they receive a subsidy after the controls. Similarly, in case of a disaster, the farmers submit a declaration of the affected parcels to the respective IOs, and after the control, they receive a compensation. Therefore, the PAs and IOs have to perform thorough and precise controls of the crop types, the parcel extent, as well as the extent of the destroyed agricultural area, in compliance with the EU regulations. Until now, most of these control checks were carried out by field visits, burdening the administration's budget. Onsite 
filed inspections may determine the eligible areas for subsidy or compensation precisely, however they require a lot of effort and time and some factors like the adverse weather conditions, or remote areas, may cause large delays in the payments, which has an impact on the agricultural processes and development of the country. [1,2]. Lately, the control efforts involve the examination of satellite imagery, but this refers to very high-resolution commercial imagery and visual image interpretation or rare case image classification of single-date images [3]. These procedures improve the control efforts in some cases, but they have a high cost and their effectiveness relies mostly on the skills of the photo-interpreter and therefore cannot always offer timely, reliable, and robust results [4].

There are several attempts for automating the mapping procedures in agriculture-related applications. For example, in terms of crop types mapping, the EU is coordinating the Monitoring Agricultural Resources (MARS) initiative [5] with the help of the Joint Research Center (JRC) in order to facilitate the coordination of the CAP. In the framework of MARS and following guidelines from the JRC, each EU member state is building a geographic information Land Parcel Identification System (LPIS) by interpreting very-high-resolution satellite images. Along with LPIS, the JRC is in charge of the image acquisition and it provides scientific and technical support in Controls with Remote Sensing, CwRS [6]. Despite the existing efforts, at the time of this paper, there is no single crop types mapping solution to be adapted in a national or international scale and one of the issues hindering this effort is the lack of common input data.

Copernicus Sentinel data bring in some effective solution to agricultural applications by providing data with systematic global coverage and under the same viewing angles. Due to their spectral resolution and high revisit frequency, the Sentinels can provide valuable qualitative and quantitative indications of environmental properties, including monitoring of vegetation [7] and mapping of floods/fire extent $[8,9]$. Sentinel-1 is a polar-orbiting radar imaging mission, operating and providing radar data in all weather conditions and day and night, since April 2014 and April 2016. Sentinel-2 is a polar-orbiting, multispectral high-resolution imaging mission with two satellites operating since June 2015 and March 2017. The effective handling of long Sentinel time series has attracted a great scientific interest, but still, the development of accurate automated techniques is limited and there are no ready-to-use tools available at the moment of this paper.

Although, there are numerous methods available for various different agricultural applications, there is still a lot of effort needed to design a sophisticated system, which can be adopted by PAs and IOs for the proper allocation of subsides and compensations [10]. Most of the available GIS (Geographic Information Systems) and remote sensing software tools do not offer built-in functionalities to easily process satellite imagery and if so, these are not optimized to support the fair payment of the farmers. Satellite mapping, production of land cover maps, and change detection analyses can be carried out with image processing software (e.g., SNAP, https://step.esa.int/main/toolboxes/snap/; ENVI, http://www.exelisvis.com/; IDRISI, http://clarklabs.org/; QGIS, https://qgis.org; GRASS, http: //grass.osgeo.org/; ORFEO Toolbox, https://www.orfeo-toolbox.org/) and statistical packages (e.g., R http://www.r-project.org/; MATLAB, http://www.mathworks.it/). These software packages provide various tools for remote sensing or GIS applications. However, in order to implement agricultural applications with these, advanced image processing skills, specific knowhow or programming skills, and long development efforts are needed. Employees of PAs/IOs often do not possess these skills and expertise. Therefore, there is an emerging need for custom-built solutions and one-package tools that include specific sets of processing functions to perform the satellite image analysis for crop type mapping and for mapping the agricultural area affected by a natural disaster. A recent review [11] presents several examples of DSS for agricultural applications, but these are usually addressing the farmers, farm advisers, or agronomists. They identify four tools that address policymakers [12-15], but still none of these address the PAs or IOs for crop type mapping or for mapping of affected agricultural areas by natural disasters.

Regarding the crop type mapping, some recent projects focus on the exploitation of Copernicus Sentinel data. The Sen2-Agri project [16] proposes a processing chain at parcel level with Sentinel-2 
imagery for near real-time agriculture monitoring, which has been tested in different sites (i.e., Argentina, Belgium, China, etc.). The RECAP project aims to provide on one hand, information to authorities and agricultural consultants, and on the other hand, assists farmers' decisions according to CAP regulations and prerequisites $[17,18]$. The Sen 4 CAP project attempts to incorporate Sentinel data in order to support the aims of modernizing the new CAP post-2020 by focusing in developing advanced algorithms and effective workflows [19]. However, the operational capacity of the proposed workflows of these projects have not been fully assessed and in recognition of the complexity of the problem, the discussions of PAs have not yet reached to a conclusion.

Copernicus in view of monitoring the impact of disasters, offers a set of observation data and measurements from field visits related to such an event. For this purpose, the Copernicus Emergency Management Service [20] offers valuable disaster maps for affected areas upon' request of authorized users (national representatives), by using mainly Sentinel data. However, this service is activated under certain conditions, it has to meet certain requirements, (i.e., extent, damages, duration, etc.), it cannot map all the disaster events, and is not dedicated to agricultural areas. There are several methods published for mapping the extent of areas affected by flood and fire events using satellite data. Examples in the literature include the use of satellite data for mapping the extent of a burned area using optical and thermal sensors of different spatial resolution [21-24] and many methods are particularly developed for Sentinel data (e.g., $[25,26])$. Various approaches were developed for example for the automatic flood detection $[27,28]$, and the free and open access policy of Copernicus Sentinel-1 triggered the development of more [29-31]. An important asset for monitoring disasters of the Sentinel-1 constellation is the frequency of data acquisition (six days) and the fact that they can be downloaded within an hour and 24 hours of reception depending on the severity of the event. This information can play a critical role during and after the occurrence of an event and offers the possibility to plan immediate action. Despite the individual efforts, there is still no solution for using Sentinel imagery for mapping the extent of the agricultural areas affected by fire or flood events that can be easily adapted by the IOs.

The DiAS (Disaster and Agriculture Sentinel Applications) project proposes a Decision Support System (DSS) to assist the authorities to make decisions on farmers' subsidies and compensations providing separate functionalities with the possibility of synergy. Interaction, discussions, and consultation with inspectors of the Greek PAs and IOs in a participatory approach allowed the effective development of user-oriented methods and tools. The methodologies for crop type mapping and detection of agricultural areas affected by fire and flood events developed by the DiAS project are implemented in a DSS prototype. The main objective of this work is to adapt state-of-the-art algorithms with the use of Copernicus Sentinel data to promote their use by the respective PAs and IOs. Therefore, the main aim is to include the users in a DSS development process in a participatory approach and pave the way for further development of similar tools, keeping them user oriented. The DiAS DSS prototype and its functionalities are presented below, along with an outline of the corresponding processes implemented within the prototype.

\section{Materials and Methods}

\subsection{The DSS Prototype Design}

Decision support tools are meant to assist users during decision making by visually or numerically illustrating possible outcomes and providing logical decision steps [32]. They can be software tools that aid decision, by providing structured qualitative and quantitative information in an explanatory manner. For authorities involved in the agricultural sector, such tools can facilitate the effective management of resources by analysing data properly and by generating a series of evidence and recommendations, acting as supplementary information sources for decision support.

The DiAS DSS prototype was designed to answer to the requirements set by non-remote sensing experts working in agricultural PAs and IOs. Figure 1 graphically illustrates the design of the DiAS 
DSS prototype and its main functionalities. The grey box represents the DSS and the white box, on the right-hand side, refers to the users, who are responsible for crop subsidies (PAs) and compensations in case of natural disasters (IOs). The DSS was designed according to the user requirements, meaning that the corresponding Greek PAs and IOs were involved in the design process in a participatory approach (see Section 2.3 for more details).

Two separate functionalities concern the crop type mapping (green box in Figure 1) and the mapping of areas affected by fire/flood events (blue box in Figure 1). Time series of Sentinel-2 imagery is involved in the crop type mapping process, while Sentinel- 1 and Sentinel-2 imagery acquired on dates before and after the event is used for the natural disasters mapping. Details on the methods implemented in the DSS functionalities are described in the following subsections (Sections 2.2 and 2.3). Geospatial information on the agricultural parcels and the farmers declarations for the area of interest is a necessary input of the DSS. This information is generally available to the authorities in a geospatial format and it is thus expected to be provided directly by the users. In many cases (including the case of Greece), the PAs responsible for the farmers' subsides are different from the IOs that are responsible for the compensations in case of a disaster. Therefore, the two main functionalities of the DSS are separated and they can be applied individually without the need to interact, share data, or even perform at the same area of interest. The user can choose to run one or both functionalities and the outputs of the DSS are discrete, but can be used together if so desired. More information on the two functionalities and the methodologies implemented in the DSS follow in the next subsections. The DSS result is the output of the Sentinel images analysis and aims to assist decision on subsides and compensation relies, while the final decision remains on the user, who should analyse the DSS output to reach a conclusion.

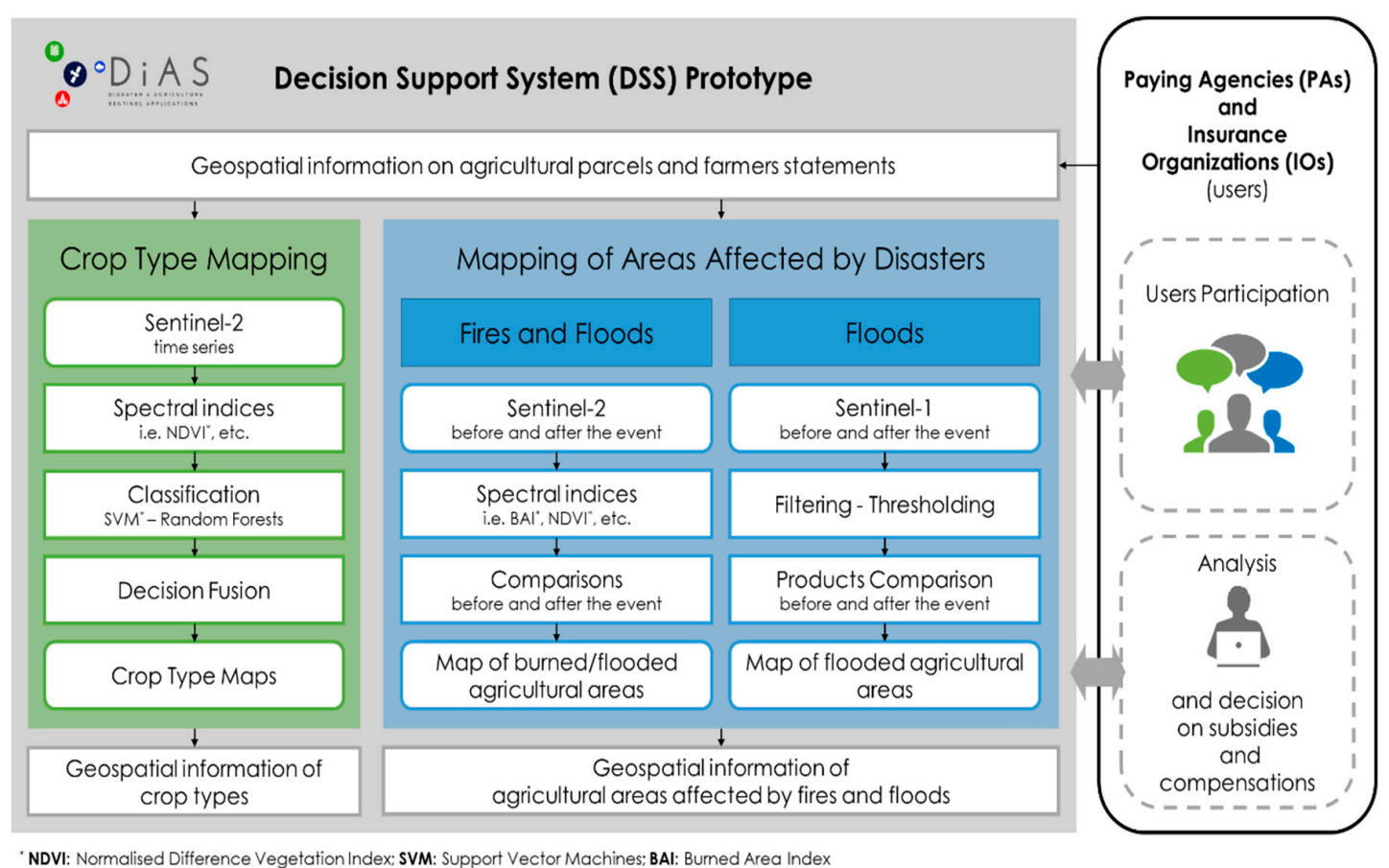

Figure 1. Graphical representation of the Disaster and Agriculture Sentinel Applications (DiAS) Decision Support System (DSS) prototype and its main functionalities. Two separate workflows describe the mapping of crop types (green box) and the mapping of areas affected by fire and flood events (blue box). The DSS prototype is designed according to the user requirements. Different types of Sentinel imagery is used for both functionalities, along with geospatial information describing the agricultural parcels of the area of interest. The analysis outputs (crop types map and the extent of the area affected by fires/floods) is available to the users, to assist on the decisions on subsidies and compensations. 


\subsection{Crop Mapping Functionality Overview}

One of the functionalities of the DiAS DSS prototype is the analysis of Sentinel imagery time series for crop type mapping. As mentioned earlier, the crop type mapping functionality is meant to assist the Pas efforts in performing controls, and to reduce, or ultimately eliminate, the number of field-visits.

There are several issues to be addressed while discriminating crop types from satellite imagery, which result in a complex mapping procedure. Crop phenology and the dynamic of vegetation is the main difficulty when dealing with crop identification, as the spectral behaviour of every crop type varies at each growth stage. Different types of crops may be in the same phenological stage and thus they may present similar spectral properties in a satellite image at a given time. Therefore, classifying crop types based on single-date images cannot provide reliable results, even if the images are acquired at critical crop development stages. Moreover, parcels of the same crop may be at a different stage of development at a given time due to different agronomic practices, different soil composition, etc., imposing spectral variability among parcels belonging to the same crop type, which causes confusion in the classification process [33]. Consequently, dense time series of satellite imagery is necessary to discriminate effectively the different crop types. Sentinel-2 can provide valuable information towards this direction, since it has a revisit rate of 5 days under the same viewing acquisition angle with two satellites in orbit [34]. Moreover, the Sentinel-2 mission orbit is sun-synchronous and minimises the effect of shadows and levels of illumination on the ground.

Figure 2 outlines the processing chain of the crop type mapping functionality included in the DSS prototype. Analysis of time series imagery imposes the use of advanced remote sensing methods to cope with the complexity of large data and the heterogeneity of spectral information over time. A workflow including pre-processing steps, image classification techniques, and post processing analysis is implemented in the DSS. The user has to select and download the appropriate Sentinel-2 imagery for the analysis, based on certain characteristics of the area of interest. The type of crops, their crop calendar, and the diversity of agronomic practices are details that are critical for the selection of the image-set and are quite familiar to the local inspectors of the PAs. In most studies, using all the available cloud-free images is recommended to account for all the varying agronomic practices which cause misclassifications $[33,35,36]$. Image pre-processing steps include the data subset to the area of interest, estimation of several radiometric indices, and image stack of the several satellite data and products. Radiometric indices like the NDVI (Normalized Difference Vegetation Index [37]), GRVI (Green-Red Vegetation Index [38]), NDWI (Normalized Difference Water Index [39]), and MCARI (Modified Chlorophyll Absorption in Reflectance Index [40]) are estimated. In DiAS, in order to achieve a reliable and accurate crop discrimination, non-parametric image classification algorithms are used, because they do not require a-priori information on the data distribution. Specifically, two image classification algorithms are implemented in the DSS, i.e., the Random Forests (RF) [41] and the Support Vector Machine (SVM) algorithm [42], which are selected because of their capability and efficiency in handling long time series [4]. The RF algorithm is reported to have good accuracy results when a lot of different crop types are expected in the scene, and it has relatively short computation time. Although it can handle high data dimensionality, which is particularly useful for long time series, it is sensitive to the sampling design [43]. The results of a RF classification are usually improved when the most important features are selected [44]. On the other hand, the SVM algorithm produces satisfying results even with small training datasets (less images in the time series) and especially when few crop types are present [45]. The DSS uses a multiple classifier system that estimates the final crop type map based on majority voting, using results from both RF and SVM. This approach usually allows crop discrimination with higher credibility than using single classifier approaches [46,47]. Nevertheless, the user can interfere and select to use either RF or SVM for the crop type discrimination based on the specific data characteristics. The methodology used for this functionality is presented in [48], where different classification schemes were tested and validated against available reference data collected in-situ and overall accuracies of $855-90 \%$ were observed in all combinations of different algorithms 
(RF, SVM) and input features, with the highest accuracy (91.6\%) observed with SVM using the initial spectral bands.

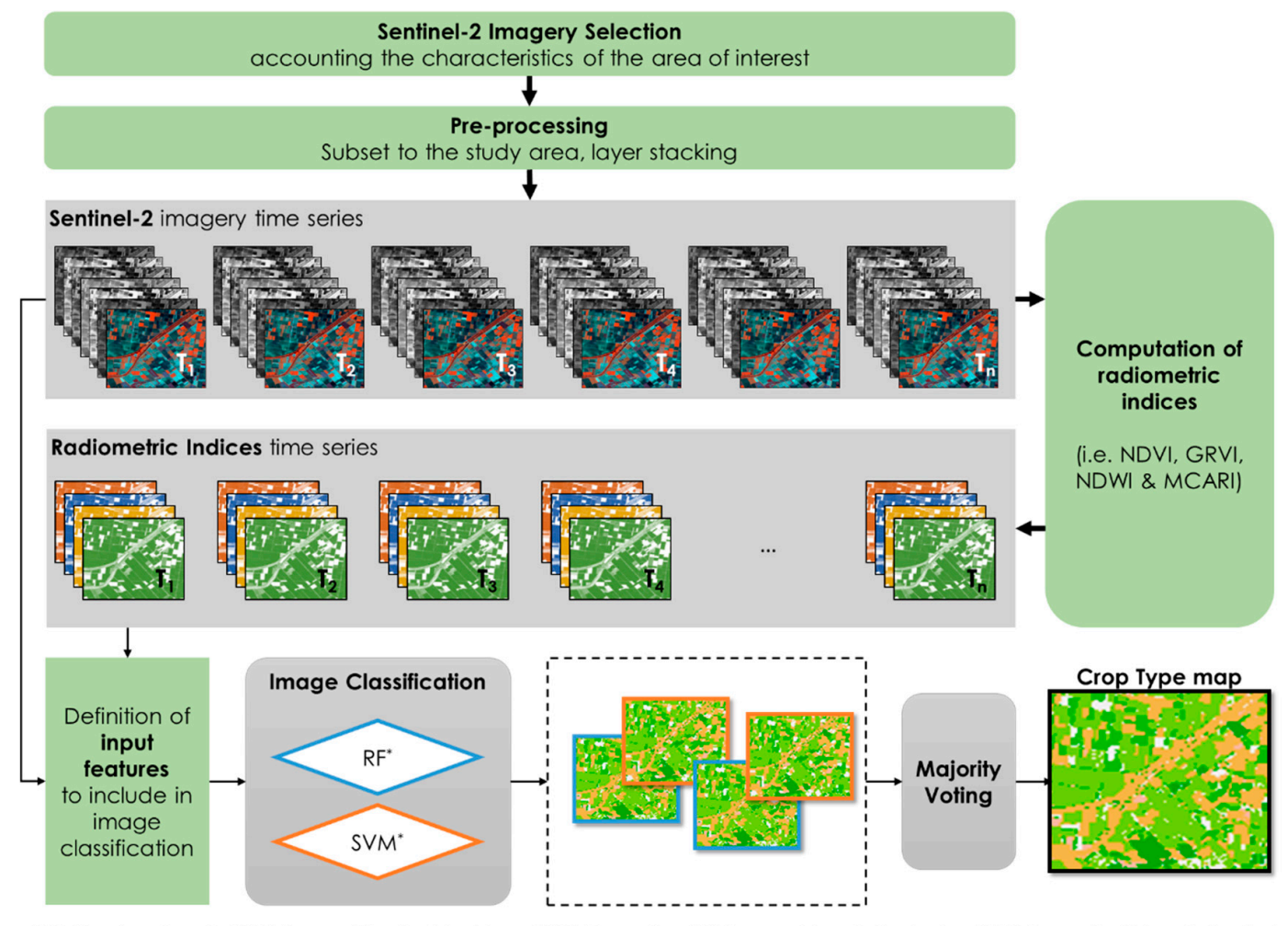

RF: Random Forests; SVM: Support Vector Machines; NDVI: Normalised Difference Vegetation Index; GRVI:Green-Red Vegetation Index; NDWI: Normalized Difference Water Index; MCARI: Modified Chlorophyll Absorption in Reflectance Index.

Figure 2. The methodology of the crop type mapping functionality of the DSS prototype.

\subsection{Natural Disasters Mapping Functionality Overview}

The second functionality of the DiAS DSS prototype concerns the assessment of agricultural areas affected by fire or flood events using Sentinel data. The natural disasters mapping functionality is meant to assist the efforts of the respective IOs in performing controls and therefore impose a better resources' management.

Concerning the effects of natural disasters on agricultural land, the extent of floods and fires in the agricultural fields can be estimated using Sentinel imagery [49]. The affected areas are detected by comparing the images acquired pre- and post- flood event by Sentinel-1 and Sentinel-2 (depending on cloud coverage). As for Sentinel-1, filtering and thresholding are implemented on the difference image of the two respective dates, to map the flooded areas. Water and vegetation indices of Sentinel-2 bands are used in order to provide ancillary information and further enhance the results of the mapping procedure. Similarly, vegetation, water, and burn area indices are integrated in the burned area mapping procedure. The methodology development for this functionality, its validation, and an example application for flood mapping are detailed in [49]. The method is validated based on the respective EMS flood products and performed well for flood area mapping [20] for two case studies in Greece (completeness 0.82 , correctness 0.79 , and quality 0.67 ).

Figure 3 graphically illustrates the processing chain for mapping the extent of the agricultural areas affected by fire or flood events in the respective DSS functionality. Sentinel-1 and Sentinel-2 imagery corresponding to before and after the disaster event are initially pre-processed. Sentinel-1 images are radiometrically calibrated to obtain backscatter values, which is required in order to extract quantitative information from radar imagery. In addition, speckle noise reduction is applied by a $5 \times 5$ Lee spatial filter, in order to minimize the salt and pepper effect and improve its interpretability. A histogram conversion from a linear to a log distribution (DN to $\mathrm{dB}$ ) facilitates the extraction of 
image information, as the distribution of the data is less skewed than in the linear scale. The final pre-processing step is the terrain correction, which eliminates the image distortions and projects pixels to the corresponding map projection. Based on the histogram the pre-processed Sentinel- 1 images, a threshold is determined, to separate the flooded areas on pre- and post-event images. Then, the logical expression is used "if 'no water' on date1 and 'water' on date2 then 'flood'"; the 'water' pixels are flagged as 'flooded' on the post-event image when they were not found to represent any type of water body on the pre-event image.

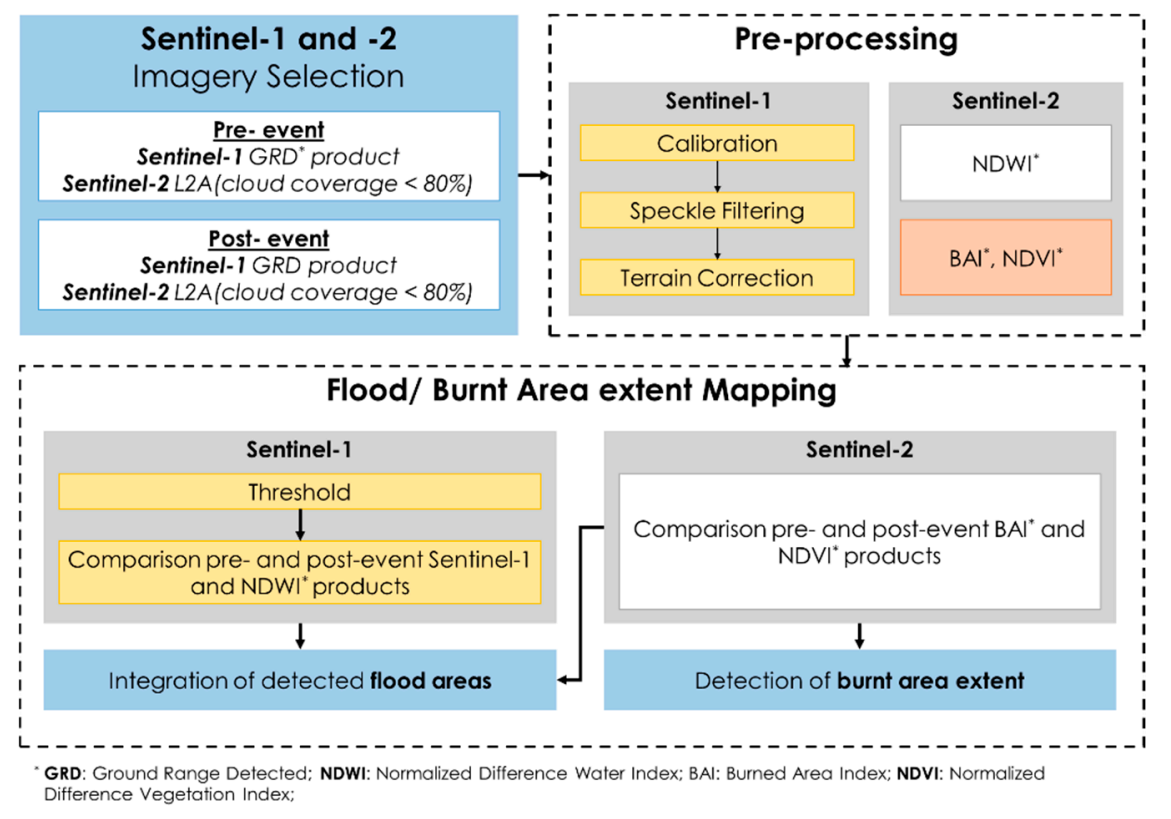

Figure 3. The methodology of the DSS prototype functionality of mapping the agricultural areas affected by fire or flood events. The yellow filled shapes correspond image processing related to flood detection, the orange one related to the burnt areas' detection, and the white ones to both.

Sentinel-2 atmospherically corrected products (L2A) can also be involved as auxiliary information in the flood mapping processing when cloud coverage does not exceed $80 \%$ before and after the event. Making use of the Normalised Difference Water Index (NDWI) [50] in Sentinel-2 imagery highlights the areas covered by water. McFeeters [50] developed the NDWI for Landsat image bands and in this study, areas corresponding to water have positive NDWI values. Generally, in the NDWI images, water areas correspond to higher pixel values compared to the remaining areas. In case of Sentinel-2 images, the positive values threshold cannot be adopted, since it results in the misclassification of building rooftops, shadows, dark objects, or asphalt, confused with water [28,51]. In order to eliminate these commission errors, the threshold for Sentinel-2 NDWI images is 0.2 , which in practice means that pixels with value greater than 0.2 are classified as 'water'. The user, though, can interfere to refine this threshold through a trial and error process for each case.

A similar Sentinel-2 image processing procedure is implemented for the burnt areas detection. Besides NDWI, the Normalised Difference Vegetation Index (NDVI) [52] and the Normalised Difference Burnt Index [26] are calculated. A comparison between pre- and post-event image indices distinguishes the burn-like areas, i.e., soil, shadows, etc., from actual burnt areas and highlights the fire impacts on the area of study.

In both cases of disasters, the water/flooded and burnt area map is finally matched with geographical information of the agricultural parcels of the area, to find the affected agricultural parcels and assist conclusions about the farmers compensations. 


\subsection{The Involvement of Users}

Environmental scientists are investigating and promoting the value of social learning processes, emphasizing on the role of stakeholders interaction, and the collaborative learning in decision making [53]. Following the trend, the development of DSSs related to agricultural applications is moving towards approaches that encourage participation to both design and implementation of representatives of different fields (e.g., [54-56]). This, in practise, means involving scientists, experts, and farmers in the design of the DSS in order to develop agricultural applications and make use of science tailored to the needs of users. At the core of the participatory approach lies the active involvement of the stakeholders as from the beginning of the research, rather than playing an exclusively passive rol of receiving knowledge [57].

For the DiAS DSS prototype to achieve its full potential, a participatory development of the DSS was performed in order to understand how stakeholders may use the tool and its outcomes. A framework based on the concepts of technological frames, interpretative flexibility, and boundary objects, was adopted [53]. The framework aims to explore and assess the different perspectives of the participating members and endorses the value of social learning for the participatory DSS development.

Two authorities in Greece, the Payment and Control Agency for Guidance and Guarantee Community Aid (OPEKEPE) and the Hellenic Agricultural Insurance Organization (ELGA) were contacted as the main stakeholders in Greece since the beginning of the project. OPEKEPE is the Greek Payment Authority of CAP Aid Schemes. It is an organization supervised by the Greek Ministry of Rural Development and Food responsible to ensure that the farmers' declarations are in compliance with European and national regulations and their fair payment. Beneficiaries are usually farmers and farmer associations, export companies, investors of the agricultural sector, manufacturing enterprises, etc. [58]. ELGA is a public legal entity operating under private Law that is fully supervised by the Greek Minister of Agriculture and is fully owned by the Greek State. It is the central body of insurance cover for agricultural holdings in Greece and its aim is to support the agricultural income of its insured persons [59].

The representatives from OPEKEPE and ELGA were invited at the beginning of the project to collaborate in the participatory development of the DSS prototype. The aim and scope of the project was outlined since the beginning and short discussions allowed the familiarization of the scientists with the current control practices OPEKEPE and ELGA are performing. More concrete information exchange was held during the first workshop organized by the DiAS team. During the workshop, the DiAS team presented, in detail, the objectives of the project, the current status of remote sensing methods and available tools, and the capabilities of Copernicus Sentinels for such applications. A brainstorming discussion session allowed the exchange of knowledge and expertise.

A questionnaire, shown in Table 1, was used as a basis for discussions and to collect qualitative data from the stakeholders for the DSS. The questions were focused around the DiAS project objectives, trying to understand the most suitable way for implementing a DSS for the PAs and IOs. It resulted from the discussions that some users already involved satellite data in their controls, mainly of very high spatial resolution by following visual interpretation procedures, which were reported to be very time-consuming and labour-intensive. The tools in use are software packages that cover a wide variety of image processing functionalities. Therefore, expert knowledge is required to choose the 'fit to purpose' functionalities, to efficiently parametrize them and to eventually develop adequate workflows. Furthermore, all available tools process satellite imagery data and deliver fixed raster or vector outputs such as the NDVI, anomaly maps, simple graphs, etc. However, they often generate data, which are difficult to interpret and do not offer flexible processing workflows adapted to meet the needs of the user. These tasks would also require programming skills that are not among the main skills of the inspectors of PAs/IOs. The participants from the PA and IO were aware of the Copernicus Sentinels and their potential for use in agricultural applications, but they had little or no experience working with Sentinel imagery. Therefore, a lot of effort would be required, before they can start including Sentinel imagery in their control procedures. In the case of mapping the affected areas by 
fires/floods, the inspectors from ELGA were familiar with the Copernicus Services and particularly the Emergency Service (EMS) [20]. They already include the relevant EMS products in their analysis for the controls, when these are available, but there are many cases where the service is not activated. Both Greek agencies agreed that there is a need to develop one-package tools that focus on specific processing methods to perform their analysis with Sentinel data. There is a clear and unambiguous need for a sophisticated set of optimized tools, which simplify complex processing and analysis of the Sentinel satellite images.

Table 1. Questions addressed to the Paying Agencies (PAs) and Insurance Organisations (IOs) as part of the participatory development of the DSS prototype.

\begin{tabular}{cl}
\hline & \multicolumn{1}{c}{ Question } \\
\hline 1 & Which are the criteria for the payment of the subsidies/compensations? \\
2 & Are you using any satellite data for the controls? If yes, in what context? Do you rely \\
3 & solely on their use? \\
4 & What kind of satellite data do you use? \\
5 & What do you know about the Copernicus Sentinels? \\
6 & Do you believe there is need for development of additional methods and tools? \\
7 & What kind of functionalities you would desire from a DSS? \\
8 & What kind of a DSS output would be useful for your controls? \\
\hline
\end{tabular}

During the second workshop, the DSS acted as a boundary object and the stakeholders from the PAs/IOs were interested in getting involved in the development of the DSS, remarking that they preferred the hands-on rather than a lecture. Having the ability to test the DSS workflows, they were able to provide specific feedback on the functionalities and the several aspects of the DSS. Certain issues were identified as the main concerns of PA and IOs. Specifically, the users required:

1. A more robust procedure for selecting suitable Sentinel data to initiate any analysis,

2. Comprehensive steps and tools for downloading the Sentinel data and applying the pre-processing analysis,

3. Tools for performing the analysis, with default set-up that can be customizable at will,

4. No need for additional GIS functionalities, since all of them are familiar with GIS software.

These points defined the main drivers of the DSS prototype implementation and were taken into account during the DSS development. Therefore, during the second workshop, the discussion cycles around the DSS resulted in co-learning amongst the participants from both sides, being actively involved in the DSS development process for improving its functionalities.

\subsection{DSS Prototype Implementation: Libraries and Components}

A prototype of the DiAS DSS is implemented as a plug-in for QGIS [60], to facilitate the participatory development with the users. The DiAS DSS prototype is functional for Windows Operating Systems, according to the user requirements in Greece, which all agreed on the operating system of preference, but it can easily be extended to other operating systems. The tool source code is implemented in Python programming language (version 3.7), with a graphical user interface as a plug-in for QGIS [60]. The GDAL/OGR (Geospatial Data Abstraction) library [61] is used within Python for the analysis of raster and vector geospatial data formats. The package NumPy [62] is used within Python for the matrix computing to allow efficient storage and manipulation of large amounts of numerical image data. The ESA Sentinel Application Platform (SNAP) [63] is used within Python to allow Sentinel image preprocessing according to the specifications of ESA. The R programming language [64] is used within Python for its efficient implementation in image classification algorithms (SVM and RF).

However, the practical implementation of the DiAS DSS prototype can be easily transferable to other platforms and operating systems, and it can also be independent from other software packages, 
since all the packages used are available as open source. The DSS prototype aims to form the basis for further development by the scientific community and ultimately the industry, therefore promoting the advent of similar tools.

\section{Results}

The participatory approach described above was used for designing and prototyping the DiAS DSS prototype. Therefore, the prototype is designed based on the needs and requirements described by the Greek PAs/IOs. Nevertheless, the remote sensing methods and tools were put together in a more generic way, aiming to provide a prototype for the development of tools for similar use by other European countries and worldwide.

The resulting DSS prototype is presented below through example applications for two case studies in northern Greece. Figure 4 shows the two sites in Greece that are used for demonstrating the functionalities of the resulting DSS prototype. The first example application concerns the crop type mapping, which is performed for an agricultural area of about $260 \mathrm{~km}^{2}$ in the Perfection of Serres, Greece. The second example application demonstrates the functionality of the DSS for assessing the effects of a flood, which occurred on 28-06-2018 in the agricultural area of Chrysoupoli, Greece.

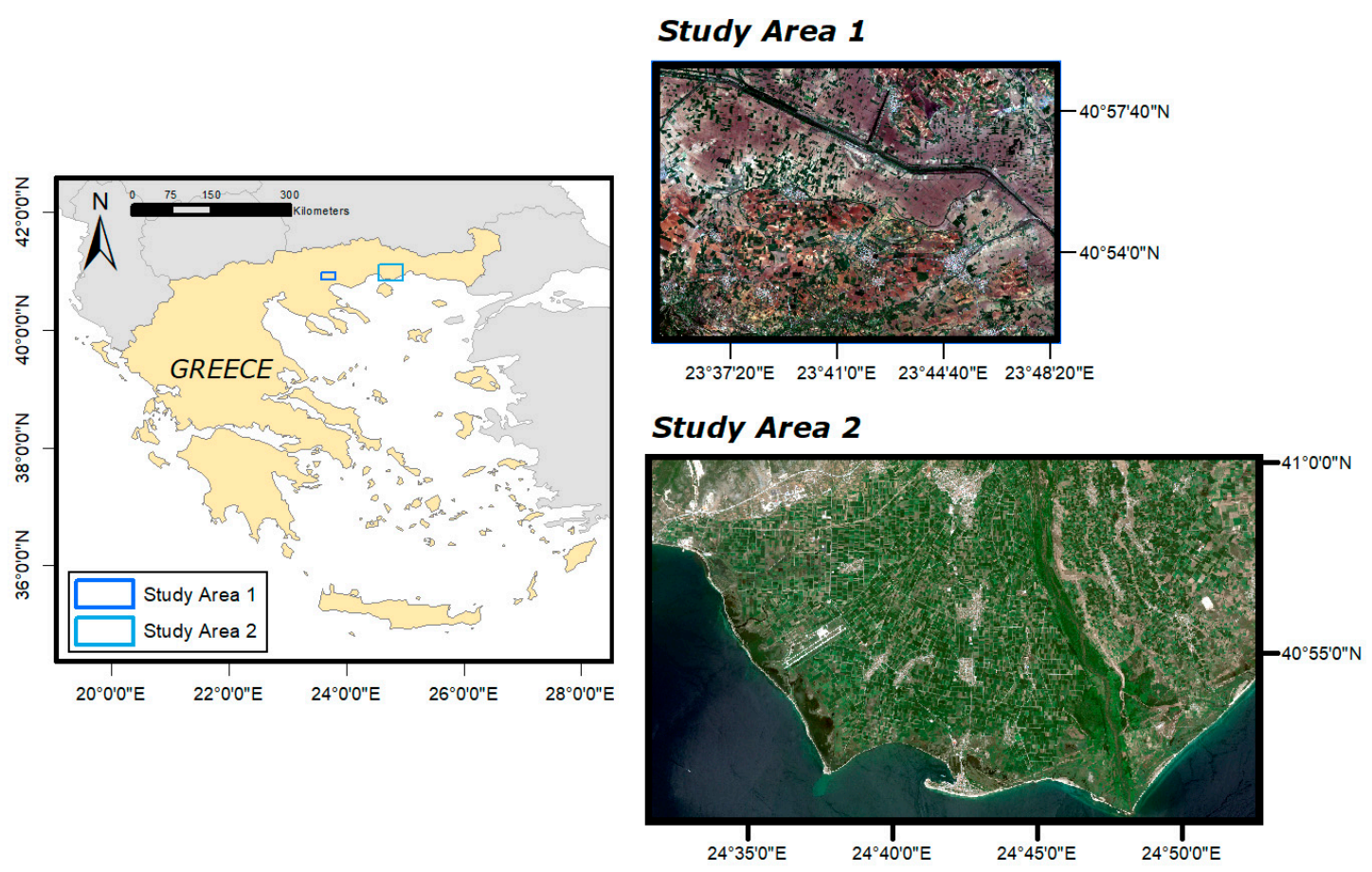

Figure 4. Example applications case studies in the northern part of Greece. True-colour composition of Sentinel-2 images over (a) an agricultural area in the Perfection of Serres used for demonstration of the crop type mapping functionality (Example Application 1) and (b) a flood event reported on 28-06-2018 in the agricultural area of Chrysoupoli for demonstration of the natural disasters effects functionality (Example Application 2).

\subsection{Crop Type Mapping_Example Application 1}

The area examined in this application example presents a diversity of crops and agronomic practices, with the main crop types being maize, sugarbeet, sunflower, cotton, wheat, and alfalfa. The first step for the application of the DSS crop type mapping functionality is the Sentinel-2 image query. The selection of the optimal dates and number of images depends on the area of interest, the variety of crop types, and the spectral heterogeneity of the crop types $[33,35,36]$. Variation in the dates of planting or harvesting is a common source of error in the image classification processes [36]. This issue can be resolved by using a dense time series of satellite imagery covering all stages of 
vegetation growth. However, including many images in the classification process results in high computational demand, especially if the area of interest is large in extent. Thus, the option of using only spectral indices and not the total information from the imagery (all the spectral bands) is also provided by the DSS. In this application example, Sentinel-2 time series imagery corresponding to 2017 was selected (Table 2), while the corresponding geospatial information from the farmers' declarations was provided by OPEKEPE. As for the selection of the imagery, one almost cloud-free image per month was selected, acquired from April to November. This dataset was considered adequate according to expert agronomists (users), since the phenology of all the involved crop types is captured even in cases of delayed planting or usage of fertilizers.

Table 2. Sentinel-2 imagery input data for Example Application 1.

\begin{tabular}{ccc}
\hline Date & Granule & Cloud Percent \\
\hline 16-04-2017 & T35TKF & 18.72 \\
$29-05-2017$ & T35TKF & 13.60 \\
$28-06-2017$ & T35TKF & 0.70 \\
$28-07-2017$ & T35TKF & 3.27 \\
$27-08-2017$ & T35TKF & 0 \\
$16-09-2017$ & T35TKF & 0 \\
$26-10-2017$ & T35TKF & 0.24 \\
\hline
\end{tabular}

The Sentinel-2 images were pre-processed according to the workflow described in Section 2.2, vegetation indices products were extracted, and all the data were combined into a single image product without the need for any parametrization from the user. The user has to provide the set of training data to describe the crops phenology corresponding to the time period in question, located in the specific study area, to train the algorithm [16]. This dataset in practice corresponds to parcels with known crop types verified by the PA. Each satellite image pixel is then classified to the crop-type-class, which best matches the temporal-spectral behaviour described by the training data. An example of the DSS prototype graphical user interface for crop types classification is shown in Figure 5.

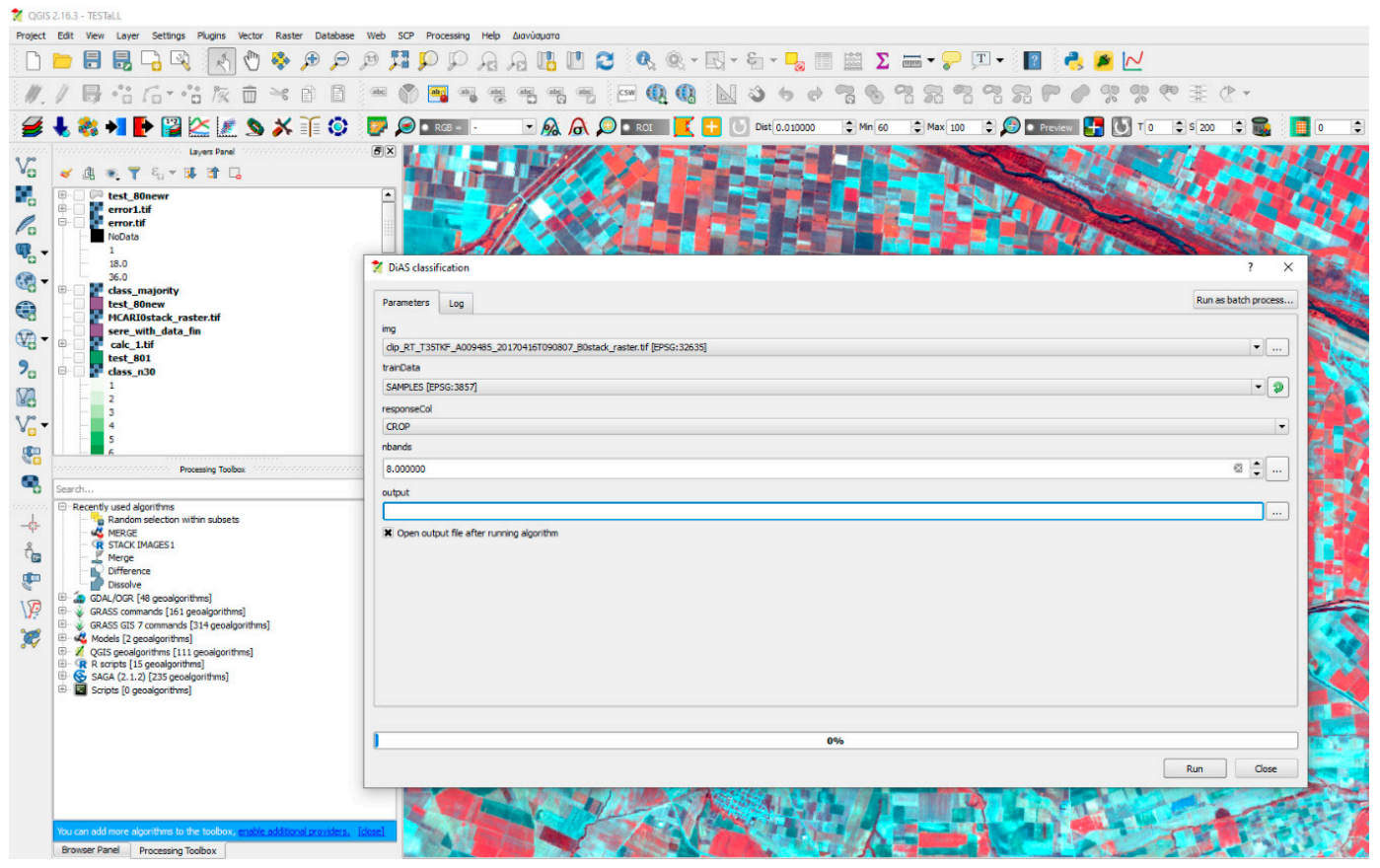

Figure 5. Example of the DSS graphical user interface for the crop mapping functionality. The functionality is applied using a GUI via QGIS. No programming skills are required by the user, who can easily parametrize the functionality using a graphical interface in a GIS environment. 
The generated map of the different crop types of the area is presented in Figure 6 as resulted by the application of the DSS functionality using the default parametrization. The main DSS output indicates the location and extend of the different crops for 2017, as these were estimated from the analysis of the Sentinel time series satellite imagery. The user has access to the intermediate products as well, such as the vegetation indices products and the individual classification maps before the application of the majority voting. This kind of information can be useful to a more advanced user for further refining the results by changing parameters like the training data or the input features (i.e., spectral bands or radiometric indices). The output of the DSS provides a strong indication of the type, location, and area of the different crops.

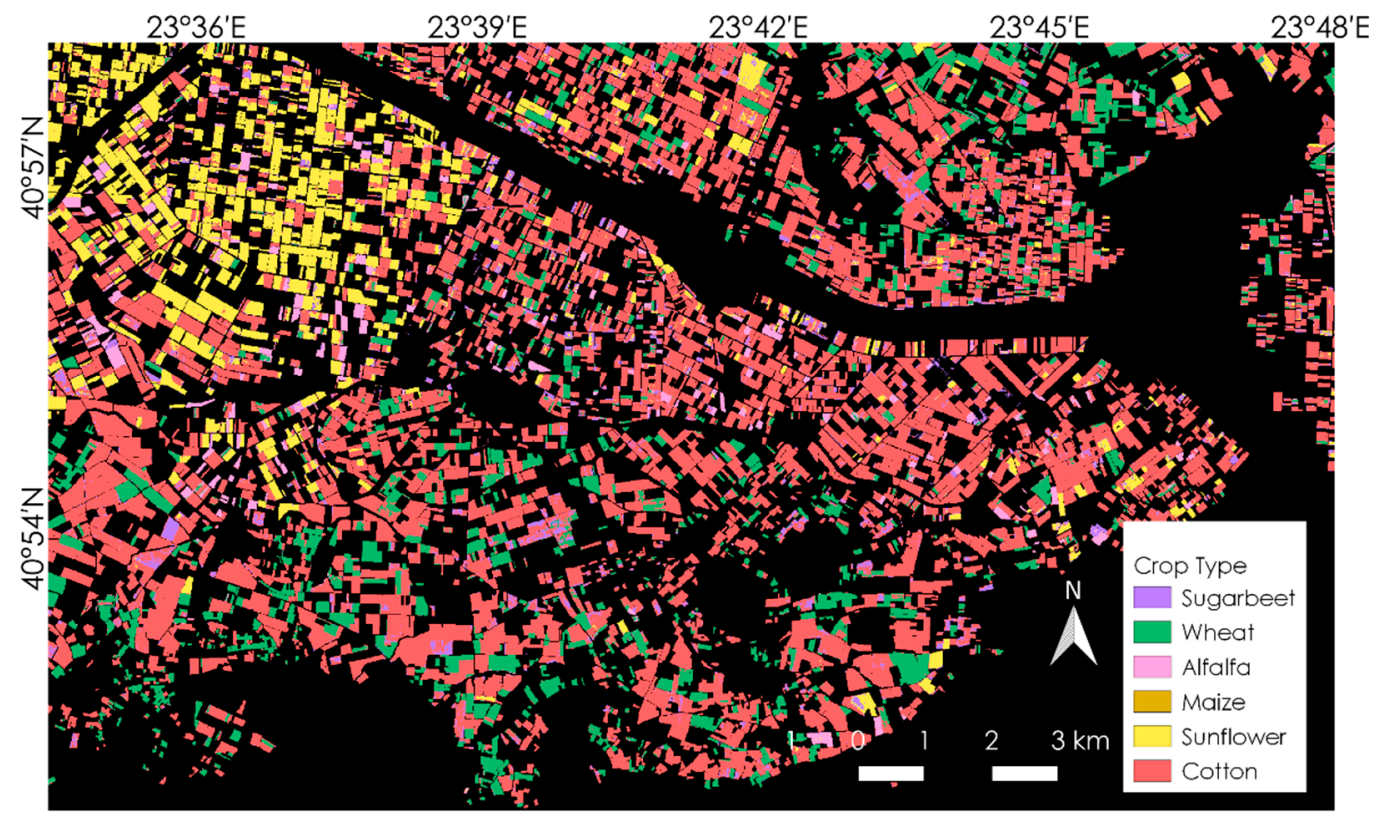

Figure 6. Crop type map resulting as a DSS output. The variety of crop types is indicated by different colours as shown in the legend. Black colour corresponds to areas that do not include any declared agricultural parcel and so they are masked out by the DSS during the processing.

\subsection{Natural Disaster Effects in Agricultural Areas-Example Application 2}

Heavy rainfalls that occurred on 28-06-2018 in the area of Chrysoupoli in Northern Greece (Figure 4) were reported to have caused the flooding of thousands of acres of agricultural land and significant parts of the road network. Few hours later, the Copernicus EMS-Mapping service [20] was activated (Activation Code: EMSR292). An example application was performed with the DSS prototype in order to delineate the agricultural areas affected by the flood event.

The first step for the application of the DSS functionality is the Sentinel image query. Sentinel-1 and, if possible, Sentinel-2 imagery, corresponding to dates before and right after the event are necessary for the analysis. Therefore, the query was performed for images corresponding to dates six days before (22-06-2018) and six days after (04-07-2018) the event in order (a) to ensure the availability of data for the analysis, given the temporal resolution of Sentinels and (b) to assess information as close as possible to the event date. The \pm 6 days threshold for imagery search in the case of natural disaster is considered adequate, but the images with acquisition date closer to (before and after) the event should be used. Cloud coverage is an important parameter for the Sentinel-2 image selection, which in the case of flood events was set to less than $80 \%$. The cloud cover threshold cannot be very low in the case of flood event mapping, because usually the days around flood events are generally cloudy. The available Sentinel images for this application example are shown in Table 3. The area of the flood event was captured by two neighbouring Sentinel-2 granules, and therefore both were included in the analysis. 
Table 3. Sentinel imagery input data for Example Application 2.

\begin{tabular}{ccccc}
\hline & \multicolumn{2}{c}{ Sentinel-1 } & \multicolumn{2}{c}{ Sentinel-2 } \\
& Pre-Event & Post-Event & Pre-Event & Post-Event \\
\hline Date & $23-06-2018$ & $29-06-2018$ & $25-06-2018$ & $30-06-2018$ \\
Product & GRD & GRD & MSI-L2A & MSI-L2A \\
Orbit & 7 & 7 & 50 & 50 \\
Granule & - & - & T35TKF, T35TLF & T35TKF, T35TLF \\
Cloud Percent & - & - & $37.00,3.15$ & $27.03,34.9$ \\
\hline
\end{tabular}

The flood extent information was derived based on all the available images (Table 3). The Sentinel-1 images were calibrated, speckle filtered, and terrain corrected as described in Section 2.3 without the need for any parameterisation from the user, using the interface shown in Figure 7. A threshold was defined to the output images and the pre- and post-event water areas were detected. A comparison between the two products ruled out the existing water bodies and highlighted the flooded areas. Similarly, assessment processing followed based on the NDWI information derived from Sentinel-2 images. The outputs of both SAR and optical images processing were combined in a single flood map of the study area (Figure 8).

The detected inundated areas by the flood event of 28-06-2018 in Chrysoupoli are presented in Figure 8 as resulted by the application of the DSS functionality using the default parametrization. The main DSS output indicates the agricultural areas that were flooded according to the analysis of the Sentinel satellite imagery. The user has access to the intermediate products as well, such as the map of water surfaces from the pre- and post- event images, before the refinement using the agricultural fields information. This kind of information can be useful to a more advanced user to further refine the results with visual interpretation and adjusting threshold values.

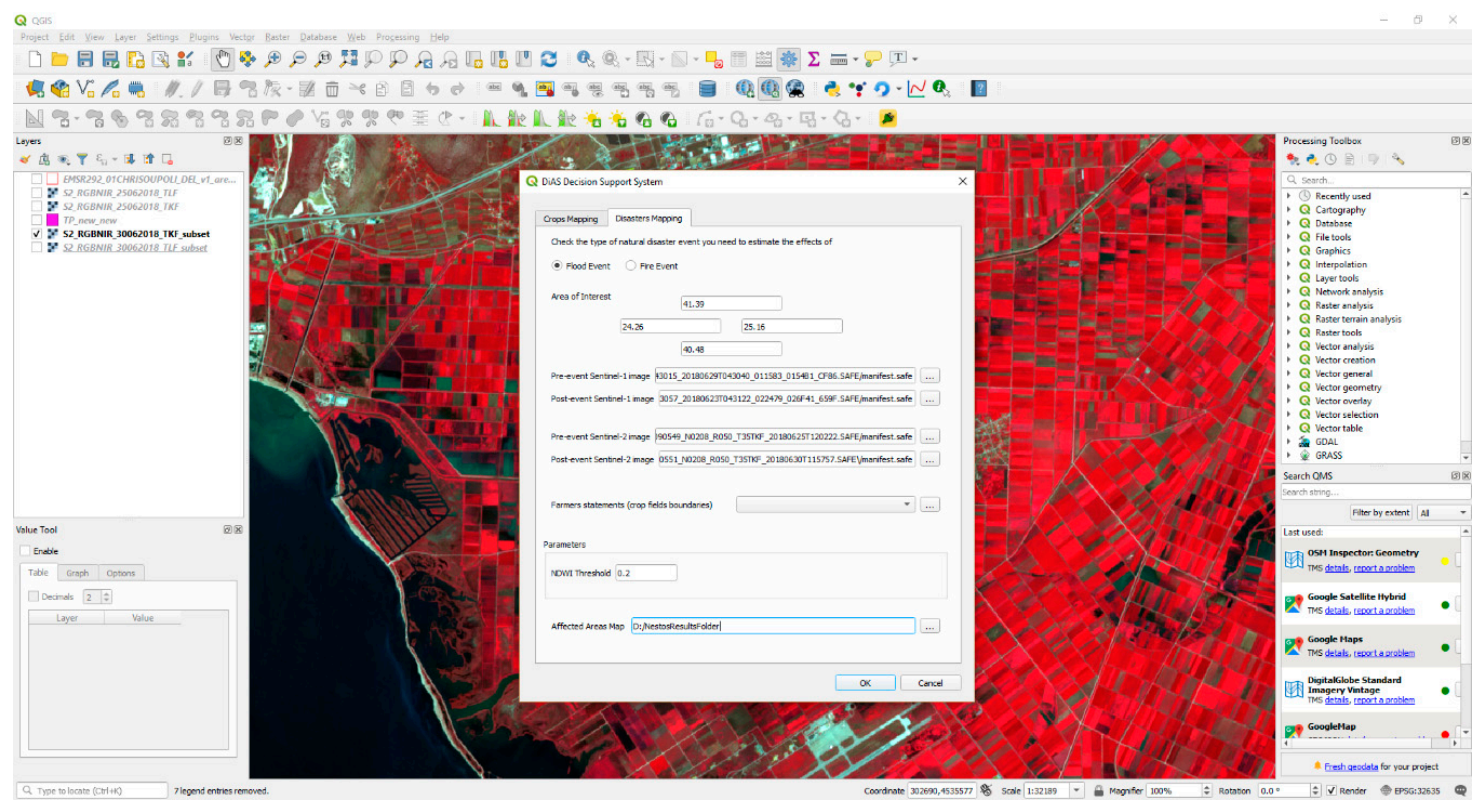

Figure 7. Example of the DSS GUI for mapping the effects of floods in agricultural areas. The user indicates the type of event (flood or fire), provides information on the area of interest, the pre- and postevent imagery, the agricultural fields boundaries of the area, and defines a folder for the output files. 


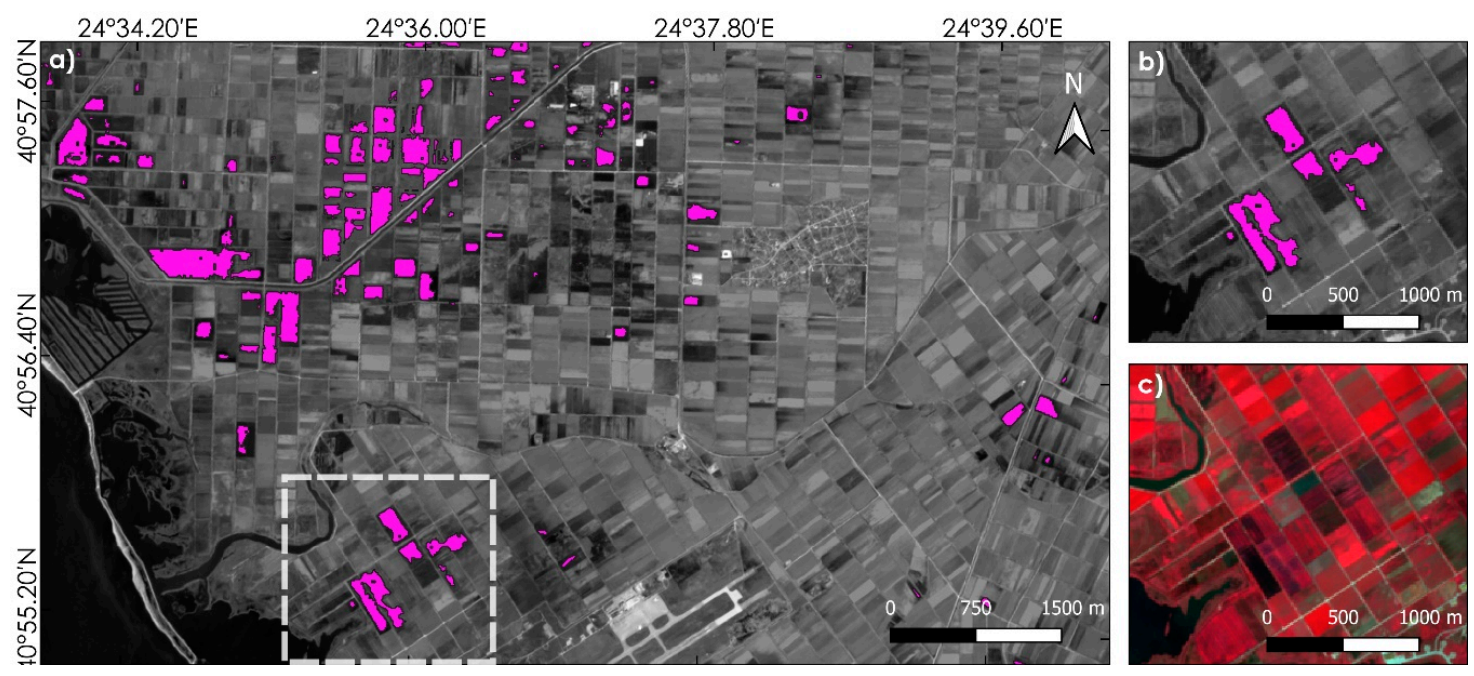

Figure 8. (a) Output of the DSS outlining the effects of the flood event on 28-06-2018 in the agricultural areas of Chrysoupoli. The flooded agricultural areas according to the analysis are indicated with pink overlaid on the Sentinel-1 image (29-06-2018).(b) Zoom in an area and (c) the respective Sentinel-2 post-event image.

\section{Discussion}

The example applications detailed in Section 3 demonstrate the DiAS DSS prototype functionalities through practical applications. Two separate functionalities were developed, as emerged from the discussions with representatives from the PA and IO. Although the initial plan was to develop a single tool for crop type mapping that would assess the area of agricultural land affected by flood and fire events as well, it turned out that such a holistic approach was not practical and useful for the respective entities. The PA and IO operate separately in Greece, but also in many European countries and worldwide, having different needs, priorities, and budgets. Therefore, although a detailed information report on the crop types and their accurate geographic location is the main interest of the PA, it is not a priority for the IO. Accordingly, the IO would not spend effort and resources in crop type mapping, they but would communicate with the PA in case this information is essential and vice versa for the PA and the agricultural areas affected by disasters. Thus, a single tool performing both tasks at the same time was not considered beneficial for the corresponding entities, as it would create more confusion, rather than facilitating the inspection efforts. Therefore, the DSS prototype was designed in a way to allow the two tasks to be performed independently. Nevertheless, the PA and IO can use both functionalities at will and in combination if necessary.

Regarding the crop type mapping tool, the representatives of the PA in Greece were rather interested in having such a tool available for use with Sentinel data. They are familiar with satellite image interpretation and aware of the capabilities of Sentinel-2 imagery for crop type mapping. However, they acknowledge the absence of easy-to-use tools that allow the introduction of Sentinel imagery in their inspections, since they lack the specific expertise on software programming, satellite image processing, and remote sensing science. Sentinel-2 holds great potential for assisting the crop type inspections and there are numerous methods available for various different agricultural applications [10], but still no common workflow, method, or tool that can be easily adopted by the PAs. The DiAS DSS prototype complements current efforts in this direction from the Sen2-Agri project [16], the RECAP project [17,18], and the Sen4CAP [19], by providing a simple workflow through an easily operated tool, with instructions that were developed in a participatory approach.

However, the performance of the implemented crop type mapping methodology depends on several factors. One of the most important is the quality of the training data. For example if a crop type is under-represented in the training dataset, it may be misclassified [65]. Therefore, the strategy of the in-situ data collection should be based on the local agronomic practices. Another point that 
the user must pay attention to is the computational cost of the image classification procedure, which increases with the areal extent of the area in consideration and the amount of satellite data to be analyzed. There are several ways to cope with the computational demand in the DiAS DSS prototype, without excluding images from the analysis. One way to reduce the processing effort is to select only one from the proposed classification algorithms (RF or SVM), rather than executing both and then use the majority voting (see details for the method in Section 2.2). The DSS uses a multiple classifier system that estimates the final crop type map based on majority voting, using results from both RF and SVM. This approach usually allows crop discrimination with higher credibility than using single classifier approaches. Nevertheless, the user can interfere and select to use either RF or SVM for the crop type discrimination based on the specific data characteristics. The selection can be done considering mainly the crop types variability and the availability of data for the algorithm training. The RF algorithm should be preferred in cases of large variability in crop types, in cases where large training samples are available and in cases of dense time series of satellite imagery [43]. The SVM algorithm can be efficient when few crop types are present in the area of interest and performs better than RF with less dense image time series [45]. Depending on the available computational resources, the number of satellite images, the extent of the area of interest, and the availability of the training data, the user can also decide on parametrizing further the DSS functionality and interfere on the input features to include/exclude part of them from the analysis. For example, the user may use radiometric indices instead of spectral bands for the analysis with a view to reduce processing time, which has proven not to deteriorate the accuracy of the results [66]. In [48], different classification schemes were tested and validated against available reference data collected in-situ for a test site in northern Greece. The performance of RF was compared to the one of SVM using different sets of input features in order to compare their efficiency in crop types classification. Generally, the RF algorithm (85\%-91.6\%, overall accuracy), performed better than SVM in all cases. Regarding the different indices, the NDVI outperformed $(90 \%)$ the rest of the indices and it is a good option when the processing time is an important issue. Nevertheless, the highest accuracy was achieved using the initial spectral bands $(91.6 \%)$. Based on these facts, the user can interfere and decide on which classifier to use and whether to include spectral bands or indices.

Regarding the disaster mapping functionality of the DSS, the developed approach is an assisting tool to detect and locate inundated and burnt agricultural areas after a disaster event. The functionality is built in a way that reflects the skills of the IO employees who lack remote sensing and/or programming expertise. By defining as input data the area of interest and the date of the event, the affected regions are delineated, and the IO inspectors can limit field visits to these specific areas. IOs are following similar strategy based on Copernicus EMS outputs, but the service is activated only under certain conditions and with unambiguous accuracy for these purposes [38]. Therefore, the DiAS DSS prototype is developed to provide information on demand whenever needed after a disaster event.

The proposed flood monitoring methodology integrates information from Sentinel-1 and/or Sentinel-2, which shows great potential in case of cloud coverage. The acquisition time of the satellite data is critical for flood mapping applications, because water recedes with time. Sentinel- 1 acquisitions are not affected by the cloud cover and are the most preferred option for monitoring the flood condition. If cloud-free Sentinel-2 data are also available near the peak flood time, the accuracy of the mapping procedure increases. In the case of areas affected by fire, Sentinel-2 data are necessary. Since more time is needed to recover from a fire event, Sentinel- 2 with its frequent revisit rate enables accurate mapping of the fire effects in agricultural land. The intermediate products of the disasters mapping procedure are again available to the user. Therefore, given the available satellite imagery, the intermediate and final products and the knowledge of the area under consideration, the user can parameterize further the DSS if necessary.

Regarding the accuracy of the DSS prototype products, the users participating in its development explicitly stated that they cannot "solely rely" on automatic algorithms and methods for their controls, even if they had an indication on the accuracy of the products. However, they claimed that products 
like the ones of the DiAS DSS prototype provide assistance to their decisions and help them to design a good field control plan. Since many of their decisions rely on their photo-interpreting abilities, when it comes to Sentinel data of $10 \mathrm{~m}$ spatial resolution, a crop types map derived from time series of data would provide valuable information and save them a lot of time and resources with their decisions. Not only the final maps, but also the intermediate products of the DSS prototype may be useful, as the users indicated. For example, the processed satellite images pre- and post- a flood event are used along with the final "affected area product" to better design the field control campaigns. Moreover, while discussing the accuracy of the DSS products, the issue of products uncertainty was raised. There seemed to be quite a lot of confusion among the participants in discriminating between accuracy and uncertainty. As a result, the users consulted not to include information on the uncertainty.

Generally, the DiAS DSS prototype provides a tool for accessing the information of the Sentinel imagery for crop type mapping and for assessing the areal extent of agricultural areas affected by flood or fire events. The user only needs to download the necessary Sentinel data and the analysis can then be performed easily using the predefined parameterization. The DSS allows access to the individual intermediate products as well, allowing further assessments and parameterization by the user, if so desired. The methods and algorithms implemented in the DSS are all validated $[48,49]$, but their application for different geographic areas, different crop types, different soil types, etc., introduce uncertainties that need to be accounted for. Therefore, the final decision must be taken by the PA and IO. The DSS aids the PA and IO efforts, by introducing easy access to methods to exploit Copernicus Sentinel data by free and open source operational modules.

Several advancements can be considered in order to improve the quality of the DiAS DSS prototype functionalities and the system itself. For example, more features can be included in the image classification procedure of the crop types mapping functionality, like texture features [67], always keeping in mind to have the algorithms' parameterization as minimum as possible, after the users' requirements. Moreover, implementing such a DSS in a cloud computing and storage infrastructure like the EC Copernicus Data and Information Access Services (DIAS) [68] would make it even more efficient, since the data downloading and preprocessing will be avoided and all the computations will be accelerated. Overall, the DiAS DSS prototype aims at demonstrating the necessity for the development of similar tools, as this emerges from the users' requirements and provides a prototype to stimulate and inspire further research and development.

\section{Conclusions}

This paper describes a decision support tool prototype for facilitating the effective management of resources by the PAs and IOs, based on the analysis of Copernicus Sentinel imagery. The DSS prototype provides two separate functionalities, one that performs crop type mapping using time series of Sentinel-2 imagery and another one that assesses the extent of agricultural areas affected by fire/flood events using Sentinel-1 and Sentinel-2 imagery.

The crop type maps are meant to be used by the respective PAs for control purposes, to reduce, and ultimately eliminate, the number of in situ visits. The maps of agricultural areas affected by fire or flood events are meant to be used for control purposes, by the respective IOs, to effectively guide the inspections and therefore to impose better management of the resources. The DiAS DSS prototype is designed based on the needs and requirements described by the Greek authorities, but it is still built in a more generic way, aiming to provide a prototype of tools to be developed for similar use for other European countries and worldwide. A participatory approach with the Greek PAs and IOs allowed assessing the needs and requirements of the users, and also collecting feedback on the tool functionalities.

Overall, the DSS is expected to pave the way for support in the decision making of the payment of agricultural aid and reimbursement. Exploiting free satellite data reduces the number of field visits, which results in reducing the overall cost and reducing the payment delays. The automation of the satellite image processing may contribute significantly to fast decision-making not only for Greece, 
but every country interested in supporting agricultural productivity. The DiAS DSS is a prototype tool aiming to form the basis for further development. It can be extended with new algorithms and methodologies for monitoring agricultural areas either for crop type mapping or for disaster impacts estimation and it can be further enhanced according to the needs and requirements authorities and policy makers in Europe and worldwide.

Author Contributions: Conceptualization, Z.M., S.S., G.D., and P.P.; methodology, S.S and G.D.; software, Z.M., S.S., and G.D.; validation, S.S and G.D.; resources, P.P.; data curation, S.S., G.D.; writing —original draft preparation, Z.M, S.S., and G.D.; writing - review and editing, Z.M, S.S., G.D., and P.P.; project administration, P.P.; funding acquisition. All authors have read and agreed to the published version of the manuscript.

Funding: This research is co-financed by Greece and the European Union (European Social Fund- ESF) through the Operational Program «Human Resources Development, Education and Lifelong Learning 2014-2020» in the context of the project "Disaster \& Agriculture Sentinel applications- DIAS" (MIS 5004813).

Acknowledgments: The authors would like to thank the Greek Payment Agency 'OPEKEPE' for providing reference data from the Land Parcel Identification System (LPIS).

Conflicts of Interest: The authors declare no conflict of interest.

\section{References}

1. Altieri, M.A.; Farrell, J.G.; Hecht, S.B.; Liebman, M.; Magdoff, F.; Murphy, B.; Norgaard, R.B.; Sikor, T.O. Agroecology, The Science Of Sustainable Agriculture; CRC Press: Boca Raton, FL, USA, 2018; ISBN 9780429495465.

2. Jones, J.W.; Antle, J.M.; Basso, B.; Boote, K.J.; Conant, R.T.; Foster, I.; Godfray, H.C.J.; Herrero, M.; Howitt, R.E.; Janssen, S.; et al. Brief history of agricultural systems modeling. Agric. Syst. 2017, 155, 240-254. [CrossRef] [PubMed]

3. Åstrand, P.J.; Giovanni Di Matteo, C.; Wirnhardt, A.B.B.; Vajsova, A.W.; Susanne Hain, A.K.; Simon, E. VHR Image Acquisition Specifications for the CAP Checks (CwRS and LPIS QA)-VHR Profile-Based Specifications Including VHR+ Profiles; European Commission Joint Research Centre: Ispra (VA), Italy, 2014.

4. Sitokonstantinou, V.; Papoutsis, I.; Kontoes, C.; Arnal, A.L.; Andrés, A.P.A.; Zurbano, J.A.G. Scalable parcel-based crop identification scheme using Sentinel-2 data time-series for the monitoring of the common agricultural policy. Remote Sens. 2018, 10, 911. [CrossRef]

5. JRC. Monitoring Agricultural ResourceS (MARS). Available online: https://ec.europa.eu/jrc/en/mars (accessed on 7 October 2019).

6. Commission, E. Agricultural Monitoring. Available online: https:/ec.europa.eu/jrc/en/research-topic/ agricultural-monitoring (accessed on 24 September 2019).

7. Gascon, F. Sentinel-2 for Agricultural Monitoring. In Proceedings of the IGARSS 2018-2018 IEEE International Geoscience and Remote Sensing Symposium, Valencia, Spain, 22-27 July 2018; pp. 8166-8168.

8. Uddin, K.; Matin, M.A.; Meyer, F.J. Operational Flood Mapping Using Multi-Temporal Sentinel-1 SAR Images: A Case Study from Bangladesh. Remote Sens. 2019, 11, 1581. [CrossRef]

9. Lasaponara, R.; Tucci, B.; Ghermandi, L. On the Use of Satellite Sentinel 2 Data for Automatic Mapping of Burnt Areas and Burn Severity. Sustainability 2018, 10, 3889. [CrossRef]

10. Rose, D.C.; Sutherland, W.J.; Parker, C.; Lobley, M.; Winter, M.; Morris, C.; Twining, S.; Ffoulkes, C.; Amano, T.; Dicks, L.V. Decision support tools for agriculture: Towards effective design and delivery. Agric. Syst. 2016, 149, 165-174. [CrossRef]

11. Gutiérrez, F.; Htun, N.N.; Schlenz, F.; Kasimati, A.; Verbert, K. A review of visualisations in agricultural decision support systems: An HCI perspective. Comput. Electron. Agric. 2019, 163, 104844. [CrossRef]

12. Tayyebi, A.; Meehan, T.D.; Dischler, J.; Radloff, G.; Ferris, M.; Gratton, C. SmartScape ${ }^{\mathrm{TM}}$ : A web-based decision support system for assessing the tradeoffs among multiple ecosystem services under crop-change scenarios. Comput. Electron. Agric. 2016, 121, 108-121. [CrossRef]

13. De Souza, K.X.S.; Dos Santos, A.D.; Evangelista, S.R.M. Visualization of ontologies through hypertrees. Proc. ACM Int. Conf. Proc. Ser. 2003, 46, 251-255.

14. Río, M.; Franco-Uría, A.; Abad, E.; Roca, E. A risk-based decision tool for the management of organic waste in agriculture and farming activities (FARMERS). J. Hazard. Mater. 2011, 185, 792-800. [CrossRef] 
15. Gandhi, N.; Armstrong, L.J.; Petkar, O. Proposed decision support system (DSS) for Indian rice crop yield prediction. In Proceedings of the 2016 IEEE International Conference on Technological Innovations in ICT for Agriculture and Rural Development, TIAR 2016, Chennai, India, 15-16 July 2016; pp. 13-18.

16. Defourny, P.; Bontemps, S.; Bellemans, N.; Cara, C.; Dedieu, G.; Guzzonato, E.; Hagolle, O.; Inglada, J.; Nicola, L.; Rabaute, T.; et al. Near real-time agriculture monitoring at national scale at parcel resolution: Performance assessment of the Sen2-Agri automated system in various cropping systems around the world. Remote Sens. Environ. 2019, 221, 551-568. [CrossRef]

17. Brunet, P.; Aschbacher, J.; Emiliano, M. NEREUS, The Ever Growing Use of Copernicus across Europe's Regions: A Selection of 99 User Stories by Local and Regional Authorities; European Comission and European Space Agency: Paris, France, 2018.

18. RECAP Project. Available online: https://www.recap-h2020.eu (accessed on 22 August 2019).

19. Kanjir, U.; Đurić, N.; Veljanovski, T. Sentinel-2 Based Temporal Detection of Agricultural Land Use Anomalies in Support of Common Agricultural Policy Monitoring. ISPRS Int. J. Geo-Inf. 2018, 7, 405. [CrossRef]

20. EU Copernicus Emergency Management Service. Available online: http://emergency.copernicus.eu/ (accessed on 25 August 2019).

21. Mouillot, F.; Schultz, M.G.; Yue, C.; Cadule, P.; Tansey, K.; Ciais, P.; Chuvieco, E. Ten years of global burned area products from spaceborne remote sensing-A review: Analysis of user needs and recommendations for future developments. Int. J. Appl. Earth Obs. Geoinf. 2014, 26, 64-79. [CrossRef]

22. Giglio, L.; Descloitres, J.; Justice, C.O.; Kaufman, Y.J. An Enhanced Contextual Fire Detection Algorithm for MODIS. Remote Sens. Environ. 2003, 87, 273-282. [CrossRef]

23. Xu, W.; Wooster, M.J.; Roberts, G.; Freeborn, P. New GOES imager algorithms for cloud and active fire detection and fire radiative power assessment across North, South and Central America. Remote Sens. Environ. 2010, 114, 1876-1895. [CrossRef]

24. Wooster, M.J.; Xu, W.; Nightingale, T. Sentinel-3 SLSTR active fire detection and FRP product: Pre-launch algorithm development and performance evaluation using MODIS and ASTER datasets. Remote Sens. Environ. 2012, 120, 236-254. [CrossRef]

25. Verhegghen, A.; Eva, H.; Ceccherini, G.; Achard, F.; Gond, V.; Gourlet-Fleury, S.; Cerutti, P. The Potential of Sentinel Satellites for Burnt Area Mapping and Monitoring in the Congo Basin Forests. Remote Sens. 2016, 8, 986. [CrossRef]

26. Huang, H.; Roy, D.; Boschetti, L.; Zhang, H.; Yan, L.; Kumar, S.; Gomez-Dans, J.; Li, J. Separability Analysis of Sentinel-2A Multi-Spectral Instrument (MSI) Data for Burned Area Discrimination. Remote Sens. 2016, 8 , 873. [CrossRef]

27. Martinis, S.; Kersten, J.; Twele, A. A fully automated TerraSAR-X based flood service. ISPRS J. Photogramm. Remote Sens. 2015, 104, 203-212. [CrossRef]

28. Benoudjit, A.; Guida, R. A Novel Fully Automated Mapping of the Flood Extent on SAR Images Using a Supervised Classifier. Remote Sens. 2019, 11, 779. [CrossRef]

29. Twele, A.; Cao, W.; Plank, S.; Martinis, S. Sentinel-1-based flood mapping: A fully automated processing chain. Int. J. Remote Sens. 2016, 37, 2990-3004. [CrossRef]

30. Amitrano, D.; Di Martino, G.; Iodice, A.; Riccio, D.; Ruello, G. Unsupervised Rapid Flood Mapping Using Sentinel-1 GRD SAR Images. IEEE Trans. Geosci. Remote Sens. 2018, 56, 3290-3299. [CrossRef]

31. Tsyganskaya, V.; Martinis, S.; Marzahn, P.; Ludwig, R. Detection of Temporary Flooded Vegetation Using Sentinel-1 Time Series Data. Remote Sens. 2018, 10, 1286. [CrossRef]

32. Dicks, L.V.; Walsh, J.C.; Sutherland, W.J. Organising evidence for environmental management decisions: A '4S' hierarchy. Trends Ecol. Evol. 2014, 29, 607-613. [CrossRef] [PubMed]

33. Siachalou, S.; Mallinis, G.; Tsakiri-Strati, M. A Hidden Markov Models Approach for Crop Classification: Linking Crop Phenology to Time Series of Multi-Sensor Remote Sensing Data. Remote Sens. 2015, 7, 3633-3650. [CrossRef]

34. ESA Sentinel-2 Revisit and Coverage. Available online: https://sentinel.esa.int/web/sentinel/user-guides/ sentinel-2-msi/revisit-coverage (accessed on 25 August 2019).

35. Ghazaryan, G.; Dubovyk, O.; Löw, F.; Lavreniuk, M.; Kolotii, A.; Schellberg, J.; Kussul, N. A rule-based approach for crop identification using multi-temporal and multi-sensor phenological metrics. Eur. J. Remote Sens. 2018, 51, 511-524. [CrossRef] 
36. Forkuor, G.; Conrad, C.; Thiel, M.; Ullmann, T.; Zoungrana, E. Integration of Optical and Synthetic Aperture Radar Imagery for Improving Crop Mapping in Northwestern Benin, West Africa. Remote Sens. 2014, 6, 6472-6499. [CrossRef]

37. D’Odorico, P.; Gonsamo, A.; Damm, A.; Schaepman, M.E. Experimental Evaluation of Sentinel-2 Spectral Response Functions for NDVI Time-Series Continuity. IEEE Trans. Geosci. Remote Sens. 2013, 51, 1336-1348. [CrossRef]

38. Motohka, T.; Nasahara, K.N.; Oguma, H.; Tsuchida, S. Applicability of Green-Red Vegetation Index for Remote Sensing of Vegetation Phenology. Remote Sens. 2010, 2, 2369-2387. [CrossRef]

39. Du, Y.; Zhang, Y.; Ling, F.; Wang, Q.; Li, W.; Li, X. Water Bodies' Mapping from Sentinel-2 Imagery with Modified Normalized Difference Water Index at 10-m Spatial Resolution Produced by Sharpening the SWIR Band. Remote Sens. 2016, 8, 354. [CrossRef]

40. Frampton, W.J.; Dash, J.; Watmough, G.; Milton, E.J. Evaluating the capabilities of Sentinel-2 for quantitative estimation of biophysical variables in vegetation. ISPRS J. Photogramm. Remote Sens. 2013, 82, 83-92. [CrossRef]

41. Breiman, L. Random Forests. Mach. Learn. 2001, 45, 5-32. [CrossRef]

42. Cortes, C.; Vapnik, V. Support-Vector Networks. Mach. Learn. 1995, 20, 273-297. [CrossRef]

43. Belgiu, M.; Drăguţ, L. Random forest in remote sensing: A review of applications and future directions. ISPRS J. Photogramm. Remote Sens. 2016, 114, 24-31. [CrossRef]

44. Millard, K.; Richardson, M. Wetland mapping with LiDAR derivatives, SAR polarimetric decompositions, and LiDAR-SAR fusion using a random forest classifier. Can. J. Remote Sens. 2013, 39, 290-307. [CrossRef]

45. Gómez, C.; White, J.C.; Wulder, M.A. Optical remotely sensed time series data for land cover classification: A review. ISPRS J. Photogramm. Remote Sens. 2016, 116, 55-72. [CrossRef]

46. Yalcin, H. Analysis of Agricultural Features. In Proceedings of the 2019 27th Signal Processing and Communications Applications Conference (SIU), Sivas, Turkey, 24-26 April 2019; pp. 1-4.

47. Pourdarbani, R.; Sabzi, S.; Hernández-Hernández, M.; Hernández-Hernández, J.L.; García-Mateos, G.; Kalantari, D.; Molina-Martínez, J.M. Comparison of Different Classifiers and the Majority Voting Rule for the Detection of Plum Fruits in Garden Conditions. Remote Sens. 2019, 11, 2546. [CrossRef]

48. Siachalou, S.; Doxani, G.; Mitraka, Z.; Patias, P. The Disaster and Agriculture Sentinel Application project. In Proceedings of the ESA Living Planet Symposium 2019, Milan, Italy, 13-17 May 2019.

49. Doxani, G.; Siachalou, S.; Mitraka, Z.; Patias, P. Decision Making On Disaster Management in Agriculture With Sentinel Applications. ISPRS-Int. Arch. Photogramm. Remote Sens. Spat. Inf. Sci. 2019, XLII-3/W8, 121-126. [CrossRef]

50. McFeeters, S.K. The use of the Normalized Difference Water Index (NDWI) in the delineation of open water features. Int. J. Remote Sens. 1996, 17, 1425-1432. [CrossRef]

51. Kaplan, G.; Avdan, U. Object-based water body extraction model using Sentinel-2 satellite imagery. Eur. J. Remote Sens. 2017, 50, 137-143. [CrossRef]

52. Tucker, C.J. Red and photographic infrared linear combinations for monitoring vegetation. Remote Sens. Environ. 1979, 8, 127-150. [CrossRef]

53. Jakku, E.; Thorburn, P.J. A conceptual framework for guiding the participatory development of agricultural decision support systems. Agric. Syst. 2010, 103, 675-682. [CrossRef]

54. Carberry, P.S.; Hochman, Z.; McCown, R.L.; Dalgliesh, N.P.; Foale, M.A.; Poulton, P.L.; Hargreaves, J.N.G.; Hargreaves, D.M.G.; Cawthray, S.; Hillcoat, N.; et al. The FARMSCAPE approach to decision support: farmers', advisers', researchers' monitoring, simulation, communication and performance evaluation. Agric. Syst. 2002, 74, 141-177. [CrossRef]

55. Nelson, R.A.; Holzworth, D.P.; Hammer, G.L.; Hayman, P.T. Infusing the use of seasonal climate forecasting into crop management practice in North East Australia using discussion support software. Agric. Syst. 2002, 74, 393-414. [CrossRef]

56. McCown, R.L.; Parton, K.A. Learning from the historical failure of farm management models to aid management practice. Part 2. Three systems approaches. Aust. J. Agric. Res. 2006, 57, 157. [CrossRef]

57. Massey, C.; Alpass, F.; Flett, R.; Lewis, K.; Morriss, S.; Sligo, F. Crossing fields: The case of a multi-disciplinary research team. Qual. Res. 2006, 6, 131-147. [CrossRef]

58. OPEKEPE. Available online: https://www.opekepe.gr/ (accessed on 7 October 2019).

59. ELGA. Available online: http://www.elga.gr (accessed on 7 October 2019). 
60. QGIS-A Free and Open Source Geographic Information System. Available online: https://www.qgis.org/en/ site/ (accessed on 17 January 2020).

61. GDAL/OGR (Geospatial Data Abstraction). Available online: https://gdal.org/ (accessed on 17 January 2020).

62. NumPy. Available online: https://numpy.org/ (accessed on 17 January 2020).

63. ESA. Sentinel Application Platform (SNAP). Available online: https://step.esa.int/main/toolboxes/snap/ (accessed on 17 January 2020).

64. The R Project for Statistical Computing. Available online: https://www.r-project.org/ (accessed on 17 January 2020).

65. Inglada, J.; Arias, M.; Tardy, B.; Hagolle, O.; Valero, S.; Morin, D.; Dedieu, G.; Sepulcre, G.; Bontemps, S.; Defourny, P.; et al. Assessment of an Operational System for Crop Type Map Production Using High Temporal and Spatial Resolution Satellite Optical Imagery. Remote Sens. 2015, 7, 12356-12379. [CrossRef]

66. Kobayashi, N.; Tani, H.; Wang, X.; Sonobe, R. Crop classification using spectral indices derived from Sentinel-2A imagery. J. Inf. Telecommun. 2019, 1-24. [CrossRef]

67. Lebourgeois, V.; Dupuy, S.; Vintrou, É.; Ameline, M.; Butler, S.; Bégué, A. A Combined Random Forest and OBIA Classification Scheme for Mapping Smallholder Agriculture at Different Nomenclature Levels Using Multisource Data (Simulated Sentinel-2 Time Series, VHRS and DEM). Remote Sens. 2017, 9, 259. [CrossRef]

68. European Commission. The DIAS: User-friendly Access to Copernicus Data and Information; European Commission: Brussels, Belgium, 2018.

(C) 2020 by the authors. Licensee MDPI, Basel, Switzerland. This article is an open access article distributed under the terms and conditions of the Creative Commons Attribution (CC BY) license (http://creativecommons.org/licenses/by/4.0/). 